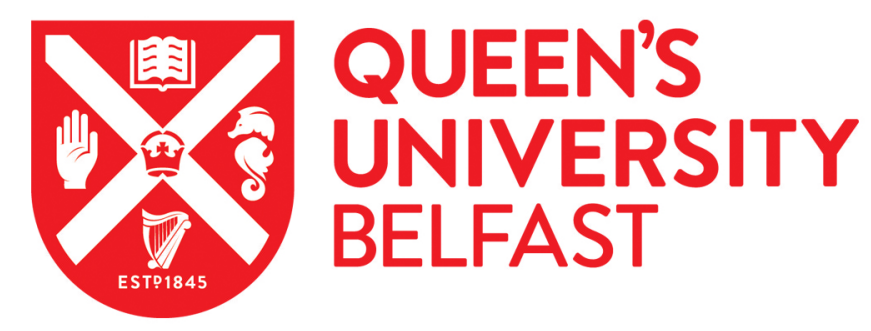

\title{
Nonsteroidal Anti-Inflammatory Drug Use is Not Associated With Reduced Risk of Barrett's Esophagus
}

Thrift, A. P., Anderson, L., Murray, L., Cook, M. B., Shaheen, N. J., Rubenstein, J., El-Serag, H. B., Vaughan, T. L., Schneider, J. L., Whiteman, D. C., \& Corley, D. A. (2016). Nonsteroidal Anti-Inflammatory Drug Use is Not Associated With Reduced Risk of Barrett's Esophagus. American Journal of Gastroenterology. https://doi.org/10.1038/ajg.2016.348

Published in:

American Journal of Gastroenterology

Document Version:

Peer reviewed version

Queen's University Belfast - Research Portal:

Link to publication record in Queen's University Belfast Research Portal

Publisher rights

(c) 2016 American College of Gastroenterology.

\section{General rights}

Copyright for the publications made accessible via the Queen's University Belfast Research Portal is retained by the author(s) and / or other copyright owners and it is a condition of accessing these publications that users recognise and abide by the legal requirements associated with these rights.

Take down policy

The Research Portal is Queen's institutional repository that provides access to Queen's research output. Every effort has been made to ensure that content in the Research Portal does not infringe any person's rights, or applicable UK laws. If you discover content in the Research Portal that you believe breaches copyright or violates any law, please contact openaccess@qub.ac.uk. 


\section{Nonsteroidal Anti-Inflammatory Drug Use is Not Associated With Reduced Risk of Barrett's Esophagus}

Short title: NSAIDs and risk of Barrett's esophagus

Aaron P. Thrift, $\mathrm{PhD}^{1,2}$, Lesley A. Anderson, PhD, $\mathrm{MPH}^{3}$, Liam J. Murray, MD, MRCGP ${ }^{3}$, Michael B.

Cook, $\mathrm{PhD}^{4}$, Nicholas J. Shaheen, MD, MPH ${ }^{5}$, Joel H. Rubenstein, MD, MSc ${ }^{6,7}$, Hashem B. El-Serag, MD, MPH ${ }^{1,8}$, Thomas L. Vaughan, MD, MPH ${ }^{9}$, Jennifer L. Schneider, $\mathrm{MPH}^{10}$, David C. Whiteman, MBBS, PhD ${ }^{11}$, Douglas A. Corley, MD, PHD ${ }^{10}$

${ }^{1}$ Section of Gastroenterology and Hepatology, Department of Medicine, Baylor College of Medicine, Houston, Texas, USA

${ }^{2}$ Dan L Duncan Comprehensive Cancer Center, Baylor College of Medicine, Houston, Texas, USA

${ }^{3}$ Centre for Public Health, Queen's University Belfast, Belfast, Northern Ireland

${ }^{4}$ Division of Cancer Epidemiology and Genetics, National Cancer Institute, Bethesda, Maryland, USA

${ }^{5}$ Division of Gastroenterology and Hepatology, University of North Carolina School of Medicine,

University of North Carolina, Chapel Hill, North Carolina, USA

${ }^{6}$ Center for Clinical Management Research, Ann Arbor Veterans Affairs Medical Center, Ann Arbor, Michigan, USA

${ }^{7}$ Barrett's Esophagus Program, Division of Gastroenterology Department of Internal Medicine, University of Michigan Medical School, Ann Arbor, Michigan, USA

${ }^{8}$ Department of Medicine, Houston VA HSR\&D Center for Innovations in Quality, Effectiveness and Safety, Michael E. DeBakey VA Medical Center, Houston, Texas, USA

${ }^{9}$ Program in Epidemiology, Fred Hutchinson Cancer Research Center, Seattle, Washington, USA

${ }^{10}$ Kaiser Permanente Division of Research, Oakland, California and San Francisco Medical Center, USA 
${ }^{11}$ QIMR Berghofer Medical Research Institute, Brisbane, Queensland, Australia

Correspondence: Aaron P. Thrift, Ph.D., Dan L Duncan Comprehensive Cancer Center, Baylor College of Medicine, One Baylor Plaza, MS: BCM305, Houston, Texas 77030-3498. e-mail:

aaron.thrift@bcm.edu

Word count: 2683 


\section{Study Highlights}

\section{WHAT IS CURRENT KNOWLEDGE}

- Epidemiological studies have consistently shown an inverse association between regular use of nonsteroidal anti-inflammatory drugs (NSAIDs) and risk of esophageal adenocarcinoma.

- However, it remains unclear whether use of NSAIDs is also inversely associated with the precursor lesion, Barrett's esophagus.

\section{WHAT IS NEW HERE}

- $\quad$ Use of NSAIDs was not associated with a reduced risk of Barrett's esophagus.

- The findings from this large pooled analysis suggest that the likely protective mechanism of NSAIDs on esophageal adenocarcinoma occurs after to the development of Barrett's esophagus. 


\begin{abstract}
OBJECTIVES: Regular use of nonsteroidal anti-inflammatory drugs (NSAIDs) is associated with a reduced risk of esophageal adenocarcinoma. Epidemiological studies examining the association between NSAID use and the risk of the precursor lesion, Barrett's esophagus, have been inconclusive.
\end{abstract}

METHODS: We analyzed pooled individual-level participant data from six case-control studies of Barrett's esophagus in the Barrett's and Esophageal Adenocarcinoma Consortium (BEACON). We compared medication use from 1474 patients with Barrett's esophagus separately with two control groups: 2256 population-based controls and 2018 gastroesophageal reflux disease (GERD) controls. Study-specific odds ratios (OR) and $95 \%$ confidence intervals (CI) were estimated using multivariable logistic regression models and were combined using a random effects meta-analytic model.

RESULTS: Regular (at least once weekly) use of any NSAIDs was not associated with the risk of Barrett's esophagus (vs. population-based controls, adjusted $\mathrm{OR}=1.00,95 \% \mathrm{CI}=0.76-1.32 ; I^{2}=61 \%$; vs. GERD controls, adjusted OR $\left.=0.99,95 \% \mathrm{CI}=0.82-1.19 ; I^{2}=19 \%\right)$. Similar null findings were observed among individuals who took aspirin or non-aspirin NSAIDs. We also found no association with highest levels of frequency (at least daily use) and duration ( $\geq 5$ years) of NSAID use. There was evidence of moderate between-study heterogeneity; however, associations with NSAID use remained non-significant in "leave-one-out" sensitivity analyses.

CONCLUSIONS: Use of NSAIDs was not associated with the risk of Barrett's esophagus. The previously reported inverse association between NSAID use and esophageal adenocarcinoma may be through reducing the risk of neoplastic progression in patients with Barrett's esophagus. 


\section{INTRODUCTION}

The incidence of esophageal adenocarcinoma has increased more than eightfold in the United States in recent decades (1), and the incidence continues to rise (2). Esophageal adenocarcinoma is a highly fatal cancer with a five-year survival rate of $<20 \%$ (3). Thus, as with other aggressive cancers, there is strong interest in identifying chemopreventive agents that might help reduce the burden of esophageal adenocarcinoma, such as nonsteroidal anti-inflammatory drugs (NSAIDs), statins, or acid suppressant medications.

NSAIDs have been shown in experimental studies to have a chemopreventive effect on the development of esophageal adenocarcinoma, presumably by blocking cyclooxygenase (COX) isoenzymes (aspirin is an inhibitor of COX-1, while other NSAIDs block both COX-1 and COX-2) and the production of prostaglandin. In addition, epidemiological studies have found a strong inverse association between use of NSAIDs and the risk of esophageal adenocarcinoma. In a pooled analysis of data from the Barrett's and Esophageal Adenocarcinoma Consortium (BEACON; http://beacon.tlvnet.org/), Liao et al. (4) showed that patients who used any NSAIDs had a 32\% reduced risk of esophageal adenocarcinoma (summary adjusted odds ratio $[\mathrm{OR}]=0.68,95 \%$ confidence interval $[\mathrm{CI}]=0.56-0.83 ; I^{2}=17 \%$ ).

Barrett's esophagus is the only known precursor for esophageal adenocarcinoma and may affect $2 \%$ of the general adult population (5). Compared to the general population, patients with Barrett's esophagus have 10- to 55-fold increased risk of developing esophageal adenocarcinoma (6-11). Assessment of risk factors for Barrett's esophagus may allow for better understanding of disease pathophysiology, and identify new opportunities for prevention and risk stratification. While NSAIDs have been consistently associated with reduced risk of esophageal adenocarcinoma, it is unclear whether they may affect risk through preventing the development of Barrett's esophagus, by preventing the development of esophageal adenocarcinoma in patients with Barrett's esophagus, or both. This question has substantial clinical implications, because attempts at chemoprevention with NSAIDs in the setting of Barrett's esophagus are only logical if the effect of NSAIDs occurs after the development of Barrett's esophagus. A recent meta-analysis of five studies showed a $30 \%$ reduction in the risk of progression from 
Barrett's esophagus to esophageal adenocarcinoma among NSAID users, as compared with nonusers (12). In contrast, results from epidemiological studies of the association between NSAIDs and the risk of Barrett's esophagus have been largely inconclusive, where both negative (13-15) and positive associations $(16,17)$ have been reported.

We therefore conducted a large analysis of pooled individual-level data from six case-control studies in the BEACON Consortium to comprehensively examine the association between use of NSAIDs and the risk of Barrett's esophagus. 


\section{METHODS}

\section{Study population}

We analyzed individual-level participant data from six population-based case-control studies in BEACON that had available data on NSAID use (Supplementary Table 1). The six studies were as follows: the Houston Barrett's Esophagus study (based at the Michael E. DeBakey VA Medical Center at Houston, TX; hereafter "Houston") (17); the Factors Influencing the Barrett's/Adenocarcinoma Relationship study (based in Ireland; "FINBAR”) (13); the Epidemiology and Incidence of Barrett's Esophagus study (based in the Kaiser Permanente Northern California population; "KPNC") (14); The Newly Diagnosed Barrett's Esophagus Study (based at the University of Michigan and Ann Arbor Veterans Affairs Medical Center at Ann Arbor, MI; "NDB") (18); the Study of Digestive Health (based in Brisbane, Australia; "SDH”) (16); and the Study of Reflux Disease (based in western Washington State; "SRD”) (19). We additionally restricted our analyses to non-Hispanic white study participants due to low numbers of cases from nonwhite ethnic groups (total $n=95$; range $n=17$ in NDB to $n=43$ in KPNC). The Institutional Review Boards or Research Ethics Committees of each institution approved the acquisition and pooling of data for the present analysis. Participants provided written informed consent to take part in the studies.

In all studies, cases included persons with endoscopic evidence of columnar mucosa in the tubular esophagus, accompanied by the presence of specialized intestinal metaplasia in an esophageal biopsy, and cases included persons with prevalent and newly diagnosed Barrett's esophagus (Supplementary Table 1). The SRD also included some patients with specialized intestinal esophageal metaplasia on biopsy, but without endoscopically visible columnar metaplasia. The NDB study included only males (cases and controls) (18).

The cases were compared separately with (1) population-based controls, representing the underlying source population from which cases arose, and (2) gastroesophageal reflux disease (GERD) controls, representing the population undergoing endoscopy from which cases are diagnosed. 


\section{Study variables}

Data for medication use was self-reported in all studies (Supplementary Table 1). Five of the six studies asked about "regular use" of medications over a specified time period with a minimum frequency of use $(13,14,17-19)$. The duration of regular use varied across the five studies, from 3 months to 1 year of use. The definition for frequency of regular use was consistent across the five studies, each specified as at least once per week. The remaining study did not define regular use; for this study we reclassified study participants as regular users if their reported frequency of use was at least once per week (16).

The main exposure categories used in the analysis were regular (at least once per week) use of the medication (aspirin, non-aspirin NSAIDs, any NSAIDs) and non-regular use (referent group; less than once per week use for each category). Medication use was further classified by frequency (weekly$<$ daily and at least daily) and duration $(<5$ years and $\geq 5$ years $)$ of use.

Potential confounding variables were available from all studies as part of a core dataset and were harmonized by the coordinating center. Variables that were selected a priori as adjustment factors included age $(<50,50-<60,60-<70, \geq 70$ years), sex (except for NDB which included only males), highest level of education (school only, tech/diploma, university), smoking status (never, former, current) and body mass index (BMI; $<25,25-29.9, \geq 30 \mathrm{~kg} / \mathrm{m}^{2}$ ). Models that compared cases with population-based controls were also subsequently adjusted for self-reported GERD symptoms (less than weekly vs. at least weekly) to evaluate potential confounding effects of GERD symptoms. Frequency of GERD symptoms was defined as the highest reported frequency of either heartburn or acid regurgitation symptoms; "frequent symptoms" were those occurring at least weekly.

\section{Statistical analysis}

We used multivariable logistic regression to estimate study-specific ORs and 95\% CIs for the association between NSAID use and risk of Barrett's esophagus. The study-specific ORs were then combined using random-effects meta-analytic models to generate a summary OR. We used the inconsistency index, $I^{2}$, 
and its $95 \%$ uncertainty interval (UI) to assess heterogeneity between studies (20). Larger $I^{2}$ values reflect increasing heterogeneity, beyond what is attributable to chance. $I^{2}$ values of $25 \%, 50 \%$ and $75 \%$ were used as evidence of low, moderate, or high levels of heterogeneity, respectively. A leave-one-out sensitivity analysis was performed by iteratively removing one study at a time to assess whether a single study was contributing to high (if present) between-study heterogeneity and to confirm that our findings were not driven by any single study (21). For comparisons with population-based controls only, we assessed whether the association between NSAID use and the risk of Barrett's esophagus was modified by frequency of GERD symptoms (less than weekly, at least weekly) by performing likelihood ratio tests of nested models with and without the NSAID-GERD interaction term.

All tests for statistical significance were two-sided at $\alpha=0.05$ and analyses were conducted using Stata 13.1 (StataCorp LP, College Station, TX). 


\section{RESULTS}

We included data from 1474 cases, 2256 population-based controls and 2018 GERD controls in the analysis. In total, $31.7 \%$ of the study population reported regular (at least once weekly) use of aspirin, $19.6 \%$ reported regular use of non-aspirin NSAIDs, and $47.0 \%$ reported regular use of any NSAIDs. However, the prevalence of use among controls (and cases) varied considerably across the six studies (Supplementary Table 2). For example, prevalence of prior regular use of aspirin in population-based controls ranged from $10.7 \%$ in $\mathrm{SDH}$ to $47.3 \%$ in NDB; in cases, from $17.0 \%$ in $\mathrm{SDH}$ to $49.6 \%$ in NDB.

\section{Aspirin}

Figure 1A shows the association between aspirin use and risk of Barrett's esophagus. In the multivariable analysis, there was no association between prior regular use of aspirin (fully adjusted OR $=1.00,95 \% \mathrm{CI}$ $=0.76-1.32$ ) and the risk of Barrett's esophagus for comparison with population-based controls (Table 1). We found moderate between-study heterogeneity $\left(I^{2}=56 \%\right)$, but with a wide uncertainty interval (95\% UI $=0 \%-82 \%)$. Among five studies that reported information on frequency of use (SDH did not capture daily medication use), prior daily use of any aspirin was not associated with the risk of Barrett's esophagus (fully adjusted $\mathrm{OR}=0.93,95 \% \mathrm{CI}=0.71-1.21$ ), with no evidence of between-study heterogeneity $\left(I^{2}=10 \%\right)$. With regard to duration of use (Table 1$)$, we found no association between duration of prior aspirin use and risk of Barrett's esophagus (fully adjusted OR for $\geq 5$ years $=1.04,95 \%$ $\left.\mathrm{CI}=0.70-1.54 ; I^{2}=59 \%\right)$. We found similar null findings for aspirin use when we compared cases with GERD controls (Table 2) and in analyses (cases vs. population-based controls) stratified by frequency of GERD symptoms (Table 3).

\section{Non-aspirin NSAIDs}

When compared with population-based controls, regular use of any non-aspirin NSAIDs was not associated with the risk of Barrett's esophagus (fully adjusted OR $=1.16,0.86-1.56 ; I^{2}=49 \%$ ) (Figure 1B). We found no evidence of effect modification by frequency of GERD symptoms (Table 3). Among 
the five studies that reported information on frequency and duration of use, we found some evidence for a modest increased risk of Barrett's esophagus associated with prior daily use of any non-aspirin NSAIDs (fully adjusted $\mathrm{OR}=1.42,95 \% \mathrm{CI}=0.92-2.18 ; I^{2}=37 \%$ ) and $\geq 5$ years of non-aspirin NSAID use (fully adjusted $\mathrm{OR}=1.57,95 \% \mathrm{CI}=1.09-2.26 ; I^{2}=7 \%$ ). However, there were no associations between frequency and duration of non-aspirin NSAID use and the risk of Barrett's esophagus for comparisons with GERD controls (Table 2).

\section{Any NSAIDs}

Using data from the six studies, there was no association between regular use of any NSAIDs (adjusted $\left.\mathrm{OR}=1.00,0.76-1.32 ; I^{2}=61 \%\right)$ and the risk of Barrett's esophagus for comparison with population-based controls (Table 1). There was no association between daily use of any NSAIDs and Barrett's esophagus (fully adjusted $\mathrm{OR}=1.01,95 \% \mathrm{CI}=0.69-1.47 ; I^{2}=57 \%$ ). With regard to duration of use (Table 1 ), we found no association between duration of prior NSAID use and risk of Barrett's esophagus (fully adjusted OR for $\geq 5$ years $=1.05,95 \% \mathrm{CI}=0.67-1.64 ; I^{2}=71 \%$ ). We found similar null findings when we compared cases with GERD controls (Table 2) and in analyses (cases vs. population-based controls) stratified by frequency of GERD symptoms (Table 3).

While there was evidence of between-study heterogeneity for associations between NSAID use and the risk of Barrett's esophagus, the results remained unchanged in the leave-one-out analysis (Supplementary Table 3), indicating that our results were not driven by any single study. 


\section{DISCUSSSION}

To our knowledge, this pooled analysis is the largest evaluation of NSAID use and risk of Barrett's esophagus to date. It included six well-characterized population-based case-control studies with similar assessments of regular medication use. We observed no overall association between regular use of any NSAIDs, as well as for the individual effects of aspirin and non-aspirin NSAIDs, and the risk of Barrett's esophagus. Furthermore, we found no evidence of an inverse relationship between increased frequency or duration of NSAID use and the risk of Barrett's esophagus. We did observe a moderate level of heterogeneity among the studies for many of the effect estimates, but with wide uncertainty intervals, and the associations with NSAID use remained non-significant when individual studies were omitted following "leave-one-out" analyses.

There is consistent evidence from epidemiological studies for an inverse relationship between use of NSAIDs and the risk of esophageal adenocarcinoma. In the largest study to date, pooled analyses of data from BEACON showed greater than $30 \%$ reduction in the risk of esophageal adenocarcinoma among NSAID users, as compared with nonusers (4). The association between NSAID use and esophageal adenocarcinoma was especially strong among daily users (adjusted $\mathrm{OR}=0.56,95 \% \mathrm{CI}=0.43-0.73$; $\left.I^{2}=0 \%\right)$. However, there remained considerable uncertainty regarding the stage(s) of neoplastic progression in which NSAIDs may act, whether in preventing the development of Barrett's esophagus, preventing progression to esophageal adenocarcinoma in patients with Barrett's esophagus, or both.

Several well designed prospective and retrospective studies have examined the association between NSAID use and risk of progression from Barrett's esophagus to esophageal adenocarcinoma. In their recent meta-analysis examining the association with NSAID use, Zhang et al. (12) showed a 30\% reduction in the risk of esophageal adenocarcinoma among patients with Barrett's esophagus (adjusted $\mathrm{OR}=0.70,95 \% \mathrm{CI}=0.52-0.95)$ with minimal heterogeneity between the five studies $\left(I^{2}=28 \%\right)$. They found no significant differences in the magnitude in the association with aspirin use or non-aspirin NSAID use and the association was independent of duration of use. 
While several observational studies have assessed the association between NSAID use and the risk of Barrett's esophagus, the results have been inconclusive. The reasons for the contrasting results are not clear and differences in populations and methods make direct comparisons between published studies difficult. We attempted to overcome some of these shortcomings by using harmonized data from multiple well-conducted case-control studies and meta-analytic methods.

The results from our study have implications for chemoprevention. If NSAIDs stopped the development of Barrett's esophagus, the target group for treatment would be $40 \%$ of the population to decrease a fraction of the 10,000 esophageal adenocarcinoma cases in the U.S. every year. Given that NSAIDs are not benign, it is unlikely that such an effort is either worthwhile or feasible. If, on the other hand, NSAIDs work after the development of Barrett's esophagus, we have a more reasonable strategy whereby we treat a much smaller group of patients at much higher risk to achieve chemoprevention.

This large pooled analysis of individual-level participant data from six case-control studies in BEACON offered several notable strengths. With almost 1500 cases of Barrett's esophagus, we had greater power to detect associations, if present, than in any of the previous single site studies. Furthermore, because we were able to evaluate NSAID exposure compared with a common reference group (non-regular use), we reduced the potential for exposure misclassification. While we observed moderate heterogeneity across studies, we found no evidence that any individual study was overly influential, thus providing additional robustness and confidence to our findings. Finally, the use of individual-level data, with variables standardized across studies, and the ability to control for a wide range of potential confounders collected consistently access the studies were additional strengths of this pooled analysis.

Our study also has a number of limitations. There was some variability among the exposure questions from different studies; in particular, the definition of regular use. We addressed the misclassification of exposure definition across the studies by using a standard definition for regular use as described in the Methods; in the one study that did not specify regular use (16), we reclassified participants accordingly. Because of the way in which the individual studies asked participants about 
medication use (e.g., "have you used NSAIDs at least weekly in the past year?"), we were unable to examine separately 'no use' versus 'low use' of NSAIDs. The individual study ORs may differ somewhat from the pooled ORs due to differences in confounding structure. For example, race was a strong confounder of the association between NSAID use and risk of Barrett's esophagus in KPNC (14). Here, we limited the analyses to non-Hispanic white study participants. Finally, most of the six studies included a mix of patients with newly diagnosed and prevalent diagnoses of Barrett's esophagus, which could have biased the results unpredictably.

In summary, this pooled analysis found no evidence for an inverse association between use of NSAIDs and the risk of Barrett's esophagus. Given the known inverse association between NSAIDs and the risk of esophageal adenocarcinoma, and analogous to that observed for colon cancer and polyps whereby NSAID use may stop progression from pre-cancer to cancer, these findings support investigations into the use of these chemopreventive agents for decreasing the risk of neoplastic progression from Barrett's esophagus to esophageal adenocarcinoma. 


\section{REFERENCES}

1. Vaughan TL, Fitzgerald RC. Precision prevention of oesophageal adenocarcinoma. Nature Reviews Gastroenterology and Hepatology 2015;12:243-8.

2. Thrift AP, Whiteman DC. The incidence of esophageal adenocarcinoma continues to rise: analysis of period and birth cohort effects on recent trends. Ann Oncol 2012;23:3155-62.

3. Thrift AP, El-Serag HB. Sex and racial disparity in incidence of esophageal adenocarcinoma: observations and explanations. Clin Gastroenterol Hepatol 2016;14:330-2.

4. Liao LM, Vaughan TL, Corley DA et al. Nonsteroidal anti-inflammatory drug use reduces risk of adenocarcinomas of the esophagus and esophagogastric junction in a pooled analysis. Gastroenterology 2012;142:442-52.

5. Ronkainen J, Aro P, Storskrubb T et al. Prevalence of Barrett's esophagus in the general population: an endoscopic study. Gastroenterology 2005;129:1825-31.

6. Conio M, Cameron AJ, Romero Y et al. Secular trends in the epidemiology and outcome of Barrett's oesophagus in Olmsted County, Minnesota. Gut 2001;48:304-9.

7. Cook MB, Wild CP, Everett SM et al. Risk of mortality and cancer incidence in Barrett's esophagus. Cancer Epidemiol Biomarkers Prev 2007;16:2090-6.

8. Rana PS, Johnston DA. Incidence of adenocarcinoma and mortality in patients with Barrett's oesophagus diagnosed between 1976 and 1986: implications for endoscopic surveillance. Dis Esophagus 2000;13:28-31.

9. Solaymani-Dodaran M, Logan RF, West J et al. Risk of oesophageal cancer in Barrett's oesophagus and gastro-oesophageal reflux. Gut 2004;53:1070-4.

10. Spechler SJ, Robbins AH, Rubins HB et al. Adenocarcinoma and Barrett's esophagus. An overrated risk? Gastroenterology 1984;87:927-33.

11. van der Burgh A, Dees J, Hop WC et al. Oesophageal cancer is an uncommon cause of death in patients with Barrett's oesophagus. Gut 1996;39:5-8. 
12. Zhang S, Zhang XQ, Ding XW et al. Cyclooxygenase inhibitors use is associated with reduced risk of esophageal adenocarcinoma in patients with Barrett's esophagus: a meta-analysis. Br J Cancer 2014;110:2378-88.

13. Anderson LA, Johnston BT, Watson RG et al. Nonsteroidal anti-inflammatory drugs and the esophageal inflammation-metaplasia-adenocarcinoma sequence. Cancer Res 2006;66:4975-82.

14. Schneider JL, Zhao WK, Corley DA. Aspirin and nonsteroidal anti-inflammatory drug use and the risk of Barrett's esophagus. Dig Dis Sci 2015;60:436-43.

15. Omer ZB, Ananthakrishnan AN, Nattinger KJ et al. Aspirin protects against Barrett's esophagus in a multivariate logistic regression analysis. Clin Gastroenterol Hepatol 2012;10:722-7.

16. Thrift AP, Pandeya N, Smith KJ et al. The use of nonsteroidal anti-inflammatory drugs and the risk of Barrett's oesophagus. Aliment Pharmacol Ther 2011;34:1235-44.

17. Khalaf N, Nguyen T, Ramsey D et al. Nonsteroidal anti-inflammatory drugs and the risk of Barrett's esophagus. Clin Gastroenterol Hepatol 2014;12:1832-9.

18. Rubenstein JH, Morgenstern H, Appelman H et al. Prediction of Barrett's esophagus among men. Am J Gastroenterol 2013;108:353-62.

19. Edelstein ZR, Farrow DC, Bronner MP et al. Central adiposity and risk of Barrett's esophagus. Gastroenterology 2007;133:403-11.

20. Higgins JP, Thompson SG, Deeks JJ et al. Measuring inconsistency in meta-analyses. BMJ 2003;327:557-60.

21. Patsopoulos NA, Evangelou E, Ioannidis JP. Sensitivity of between-study heterogeneity in metaanalysis: proposed metrics and empirical evaluation. Int J Epidemiol 2008;37:1148-57. 


\section{CONFLICT OF INTEREST}

Guarantor of the article: Aaron P. Thrift, Ph.D.

Specific author contributions: A.P.T. contributed to data analysis, interpretation of data and drafting of the manuscript. J.L.S. and M.B.C. contributed to interpretation of data and drafting of the manuscript. L.A.A., L.J.M., J.H.R., H.B.E-S., T.L.V., D.C.W., and D.A.C. designed, obtained funding and collected data from individual case-control studies, contributed to the concept of the consortium, interpretation of data and refinement of the manuscript. All authors approved the final draft submitted.

Financial support: This work was supported by the National Institutes of Health RO1 DK63616 (D.A.C.); 1R21DK077742 (N.J.S. and D.A.C.); K23DK59311 (N.J.S.); R03 DK75842 (N.J.S.); K23DK079291 (J.H.R.); R01 CA116845 (H.B.E-S.); K24-04-107 (H.B.E-S.); the Intramural Program of the National Institutes of Health (M.B.C.); an Ireland-Northern Ireland cooperation research project grant sponsored by the Northern Ireland Research and Development Office and the Health Research Board, Ireland (FINBAR) (L.J.M.: RES/1699/01N/S); the Study of Digestive Health, NCI RO1 CA 001833 (D.C.W.); the Study of Reflux Disease, NCI R01 CA72866 (T.L.V.), the Established Investigator Award in Cancer Prevention and Control, K05 CA124911 (T.L.V.), and the US Department of Veterans Affairs CSRD Merit I01-CX000899 (J.H.R.).

Potential competing interests: None. 
Figure 1. The summary odds ratios and $95 \%$ confidence intervals (CI) for the association between Barrett's esophagus and A) at least weekly aspirin use; B) at least weekly non-aspirin NSAID use; and C) at least weekly use of any NSAIDs. Summary odds ratios and 95\% confidence intervals were estimated using a random-effects meta-analytic model. All statistical tests were two-sided. \% Weight describes the weighting each study contributes to the summary odds ratio. The dot on each square represents the studyspecific odds ratio, and the size of the surrounding square is an illustrative representation of study weighting. The horizontal lines represent the confidence intervals; if ending in an arrow, this indicates that the interval transcends the region plotted. The diamond represents the summary odds ratio and $95 \%$ confidence intervals. Houston $=$ the Houston Barrett's Esophagus study; FINBAR $=$ Factors Influencing the Barrett's Adenocarcinoma Relationship Study; KPNC = the Epidemiology and Incidence of Barrett's Esophagus study; NDB = The Newly Diagnosed Barrett's Esophagus Study; SDH = the Study of Digestive Health; SRD = the Study of Reflux Disease. 


\begin{tabular}{|c|c|c|c|}
\hline Study & Questionnaire details & $\begin{array}{c}\text { Years of } \\
\text { study }\end{array}$ & Case definition \\
\hline Houston & $\begin{array}{l}\text { "Have you taken [class of mediation] at least once a week for } 3 \text { months or longer, in the last } \\
\text { year?". Subjects responding affirmatively were asked to provide start and stop dates, and } \\
\text { the frequency and duration of use. }\end{array}$ & 2008-2013 & $\begin{array}{l}\text { Newly diagnosed and prevalent cases; } \\
\text { any length; SIM. }\end{array}$ \\
\hline FINBAR & $\begin{array}{l}\text { Subjects were asked to recall if they had ever taken any prescription or over-the-counter } \\
\text { aspirin or non-aspirin NSAID at least once weekly for } \geq 6 \text { months. Subjects responding } \\
\text { affirmatively were asked to provide their age or the date when they first started taking these } \\
\text { medications regularly, when they stopped taking the medications on a regular basis, and } \\
\text { the total duration of use and the frequency that the medications were taken. Medication } \\
\text { usage is reported } \geq 1 \text { year before interview date. }\end{array}$ & 2002-2004 & 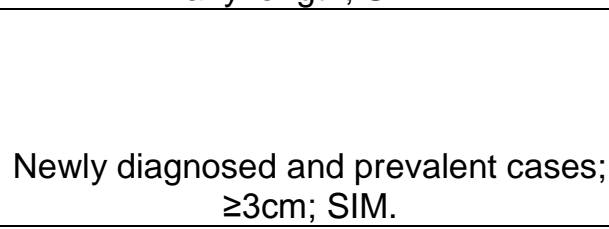 \\
\hline KPNC & $\begin{array}{l}\text { Subjects were asked to consider both prescription and over-the-counter medications when } \\
\text { responding "nonusers" for the main analyses were defined as persons with less than } \\
\text { weekly use of either aspirin or NSAIDs in the past year. Average frequency was estimated } \\
\text { using intake in the year prior to the index date. The duration of use was the interval } \\
\text { between the age at initiation of regular use (defined as use at least once a week for more } \\
\text { than } 1 \text { year) and the index date. }\end{array}$ & $2002-2005$ & $\begin{array}{l}\text { Newly diagnosed cases; } \\
\text { any length; SIM. }\end{array}$ \\
\hline NDB & $\begin{array}{l}\text { "Please fill in the table if you have ever taken any of the following prescription or over-the- } \\
\text { counter pain medicines at least once a week, for at least } 6 \text { months?" }\end{array}$ & $2008-2011$ & $\begin{array}{l}\text { Newly diagnosed cases; } \\
\text { any length; SIM }\end{array}$ \\
\hline SDH & $\begin{array}{l}\text { "How often have you taken the following over-the-counter medications during the PAST } 5 \\
\text { years?". For the BEACON analysis, "nonusers" were those that responded never using the } \\
\text { medication as well as those who reported using the medication 'occasionally', 'less than } \\
\text { once a month', or 'two to three times per month'. "Users" were those that reported using the } \\
\text { medication 'once a week', 'two to three times per week', 'four to seven times per week', or } \\
\text { 'two or more times per day'. }\end{array}$ & 2003-2006 & $\begin{array}{l}\text { Newly diagnosed cases; } \\
\text { any length; SIM. }\end{array}$ \\
\hline SRD & $\begin{array}{l}\text { "Here is a group of some over-the-counter medications that contain aspirin and are taken } \\
\text { for pain or inflammation. Have you ever taken any of them at least once a week for three } \\
\text { months or longer?". Captured frequency (how often did you usually take any of these } \\
\text { medications), start and stop dates, and total years taking medication. }\end{array}$ & $1997-2000$ & Newly diagnosed cases; SIM. \\
\hline
\end{tabular}

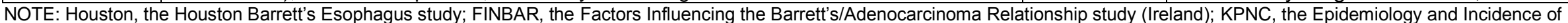

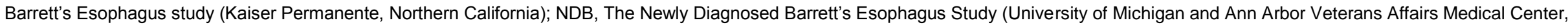

Michigan); SDH, the Study of Digestive Health (Brisbane, Australia); SRD, the Study of Reflux Disease (western Washington State). 
Supplementary Table 2 Characteristics of Controls and Cases of Barrett's Esophagus by Study

\begin{tabular}{|c|c|c|c|c|c|c|c|c|c|}
\hline \multirow[b]{2}{*}{ Variable } & \multicolumn{3}{|c|}{ Houston } & \multicolumn{3}{|c|}{ FINBAR } & \multicolumn{3}{|c|}{ KPNC } \\
\hline & $\begin{array}{c}\text { Population } \\
\text { controls } \\
(\mathrm{n}=278) \\
\end{array}$ & $\begin{array}{c}\text { BE cases } \\
(n=289)\end{array}$ & $\begin{array}{c}\text { GERD } \\
\text { controls } \\
(n=857)\end{array}$ & $\begin{array}{c}\text { Population } \\
\text { controls } \\
(n=260) \\
\end{array}$ & $\begin{array}{c}\text { BE cases } \\
(n=224)\end{array}$ & $\begin{array}{c}\text { GERD } \\
\text { controls } \\
(n=230)\end{array}$ & $\begin{array}{c}\text { Population } \\
\text { controls } \\
(n=268) \\
\end{array}$ & $\begin{array}{c}\text { BE cases } \\
(n=277)\end{array}$ & $\begin{array}{c}\text { GERD } \\
\text { controls } \\
(n=253)\end{array}$ \\
\hline Age, mean (SD) & $62.7(6.3)$ & $61.6(7.4)$ & $60.4(8.7)$ & $62.5(12.8)$ & $61.9(12.0)$ & $61.7(11.4)$ & $62.4(10.1)$ & $62.3(10.8)$ & $62.1(10.5)$ \\
\hline Male, n (\%) & $273(98.2)$ & $282(97.6)$ & $778(90.8)$ & $220(84.6)$ & $185(82.6)$ & $189(82.2)$ & $176(65.7)$ & $209(75.5)$ & $176(69.6)$ \\
\hline University education, n (\%) & $52(20.2)$ & $43(16.9)$ & $150(19.4)$ & $42(16.3)$ & $23(10.4)$ & $34(14.9)$ & $116(43.3)$ & $83(30.0)$ & $87(34.4)$ \\
\hline Body Mass Index, mean (SD) & $31.2(6.3)$ & $30.2(5.5)$ & $30.1(6.0)$ & $27.7(3.9)$ & $27.8(4.4)$ & $29.2(4.0)$ & $29.5(5.8)$ & $29.7(5.9)$ & $29.2(4.9)$ \\
\hline Ever smoker, n (\%) & $193(74.8)$ & $213(76.9)$ & $589(72.3)$ & $152(59.8)$ & $136(61.0)$ & $116(51.6)$ & $156(58.2)$ & $186(67.4)$ & $158(62.5)$ \\
\hline Weekly GERD symptoms, n (\%) & $76(29.3)$ & $171(61.7)$ & $467(57.0)$ & $15(6.8)$ & $163(76.9)$ & $90(39.1)$ & $167(62.6)$ & $256(92.8)$ & $238(94.1)$ \\
\hline Aspirin use (at least weekly), $\mathrm{n}(\%)$ & $100(45.1)$ & $101(40.1)$ & $238(31.8)$ & $75(29.1)$ & $54(24.1)$ & $66(28.7)$ & $110(41.0)$ & $109(39.4)$ & $99(39.1)$ \\
\hline Non-aspirin NSAID use (at least weekly), n (\%) & $16(6.3)$ & $14(5.3)$ & $67(8.5)$ & $32(12.5)$ & $25(11.2)$ & $36(15.7)$ & $71(27.0)$ & $73(27.9)$ & $79(31.6)$ \\
\hline \multirow[t]{3}{*}{ Any NSAID use (at least weekly), n (\%) } & $140(63.4)$ & $135(56.5)$ & $391(53.3)$ & $94(36.7)$ & $68(30.4)$ & $89(38.7)$ & $148(55.9)$ & $154(57.3)$ & $142(56.6)$ \\
\hline & \multicolumn{3}{|c|}{ NDB } & \multicolumn{3}{|c|}{ SDH } & \multicolumn{3}{|c|}{ SRD } \\
\hline & $\begin{array}{c}\text { Population } \\
\text { controls } \\
(n=640) \\
\end{array}$ & $\begin{array}{c}\text { BE cases } \\
(n=133)\end{array}$ & $\begin{array}{c}\text { GERD } \\
\text { controls } \\
(n=0)\end{array}$ & $\begin{array}{c}\text { Population } \\
\text { controls } \\
(n=618) \\
\end{array}$ & $\begin{array}{c}\text { BE cases } \\
(n=379)\end{array}$ & $\begin{array}{c}\text { GERD } \\
\text { controls } \\
(n=305)\end{array}$ & $\begin{array}{c}\begin{array}{c}\text { Population } \\
\text { controls } \\
(n=192)\end{array} \\
\end{array}$ & $\begin{array}{c}\text { BE cases } \\
(n=172)\end{array}$ & $\begin{array}{c}\text { GERD } \\
\text { controls } \\
(n=373)\end{array}$ \\
\hline Age, mean (SD) & $58.7(6.8)$ & $61.3(6.9)$ & - & $58.0(11.1)$ & $59.6(11.5)$ & $53.6(12.7)$ & $52.9(12.4)$ & $54.2(12.9)$ & $50.1(13.5)$ \\
\hline Male, n (\%) & $640(100)$ & $133(100)$ & - & $400(64.7)$ & $260(68.6)$ & $144(47.2)$ & $118(61.5)$ & $114(66.3)$ & $187(50.1)$ \\
\hline University education, $\mathrm{n}(\%)$ & $273(42.8)$ & $40(30.5)$ & - & $132(21.4)$ & $48(12.7)$ & $67(22.0)$ & $146(76.0)$ & $121(70.4)$ & $260(69.9)$ \\
\hline Body Mass Index, mean (SD) & $29.8(5.5)$ & $30.5(5.0)$ & - & $27.0(5.1)$ & $27.7(4.6)$ & $27.0(5.0)$ & $27.7(5.0)$ & $29.3(5.1)$ & $28.4(5.5)$ \\
\hline Ever smoker, n (\%) & $383(60.0)$ & $101(75.9)$ & - & $268(45.8)$ & $251(69.0)$ & $150(51.2)$ & $92(47.9)$ & $112(65.1)$ & $185(49.6)$ \\
\hline Weekly GERD symptoms, n (\%) & $214(34.9)$ & $94(71.2)$ & - & $288(49.7)$ & $309(86.3)$ & $221(77.8)$ & $153(81.4)$ & $164(95.9)$ & $361(98.1)$ \\
\hline Aspirin use (at least weekly), n (\%) & $303(47.3)$ & $66(49.6)$ & - & $66(10.7)$ & $64(17.0)$ & $31(10.2)$ & $58(30.2)$ & $70(40.9)$ & $142(38.2)$ \\
\hline Non-aspirin NSAID use (at least weekly), n (\%) & $161(25.2)$ & $46(34.6)$ & - & $73(11.8)$ & $68(18.0)$ & $42(13.8)$ & $54(28.1)$ & $79(45.9)$ & $159(42.6)$ \\
\hline Any NSAID use (at least weekly), $\mathrm{n}(\%)$ & $388(60.6)$ & $88(66.2)$ & - & $132(21.4)$ & $112(29.7)$ & $68(22.4)$ & $94(49.0)$ & $110(64.3)$ & $228(61.3)$ \\
\hline
\end{tabular}

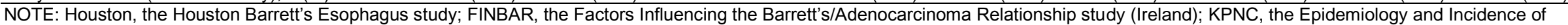

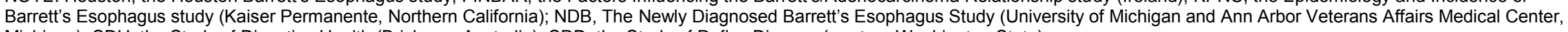
Michigan); SDH, the Study of Digestive Health (Brisbane, Australia); SRD, the Study of Reflux Disease (western Washington State). 
Supplementary Table 3 Adjusted Odds Ratios and 95\% Confidence Intervals for the Association Between At Least Weekly Non-steroidal Anti-inflammatory Drug Use and Risk of Barrett's Esophagus Compared with Population-based Controls, Leave-one-out Sensitivity Analysis

\begin{tabular}{lcccc}
\hline & & Any aspirin & $\begin{array}{c}\text { Any non-aspirin } \\
\text { NSAIDs }\end{array}$ & Any NSAIDs \\
\cline { 3 - 5 } & & OR $(95 \% \mathrm{Cl})$ & OR $(95 \% \mathrm{Cl})$ & OR $(95 \% \mathrm{Cl})$ \\
\hline \multirow{3}{*}{ Excluded study } & All studies & $1.00(0.76-1.32)$ & $1.16(0.86-1.56)$ & $1.00(0.76-1.32)$ \\
& & & & \\
& Houston & $1.00(0.70-1.41)$ & $1.24(0.93-1.65)$ & $1.04(0.75-1.44)$ \\
& FINBAR & $1.06(0.80-1.42)$ & $1.24(0.93-1.65)$ & $1.09(0.84-1.41)$ \\
& KPNC & $1.05(0.76-1.45)$ & $1.19(0.84-1.70)$ & $1.00(0.71-1.42)$ \\
& NDB & $1.05(0.76-1.44)$ & $1.10(0.75-1.60)$ & $1.03(0.74-1.43)$ \\
& SDH & $0.90(0.71-1.15)$ & $1.09(0.74-1.60)$ & $0.93(0.68-1.25)$ \\
& SRD & $0.94(0.69-1.26)$ & $1.06(0.81-1.39)$ & $0.92(0.70-1.22)$ \\
\hline
\end{tabular}

Models included terms for age ( $<50,50-59,60-69, \geq 70$ years), sex (except NDB, all male), education (school only, tech/diploma, university), smoking status (never, former, current), and body mass index $\left(<25,25-29.9, \geq 30 \mathrm{~kg} / \mathrm{m}^{2}\right)$ 
Table 1 Odds Ratios and 95\% Confidence Intervals for the Association Between Frequency of Non-steroidal Anti-inflammatory Drug Use and Risk of Barrett's Esophagus Compared with Population-based Controls

\begin{tabular}{|c|c|c|c|c|c|c|c|}
\hline & $\begin{array}{l}\text { No. of } \\
\text { studies }\end{array}$ & OR $(95 \% \mathrm{Cl})$ & $\begin{array}{c}R^{2} \\
(95 \% \text { Uا) }\end{array}$ & $\mathrm{OR}^{\mathrm{a}}(95 \% \mathrm{Cl})$ & $\begin{array}{c}P^{2} \\
(95 \% \text { UI) }\end{array}$ & $\mathrm{OR}^{\mathrm{b}}(95 \% \mathrm{Cl})$ & $\begin{array}{c}P^{2} \\
(95 \% \text { UI) }\end{array}$ \\
\hline \multicolumn{8}{|l|}{ Aspirin use } \\
\hline Nonuser (< weekly use) & & 1.00 & & 1.00 & & 1.00 & \\
\hline At least weekly & 6 & $1.09(0.84-1.43)$ & $66(18-87)$ & $1.02(0.80-1.29)$ & $50(0-80)$ & $1.00(0.76-1.32)$ & $56(0-82)$ \\
\hline Weekly-<daily & 5 & $1.11(0.78-1.56)$ & $14(0-82)$ & $1.02(0.73-1.42)$ & $8(0-81)$ & $0.88(0.62-1.26)$ & $6(0-80)$ \\
\hline At least daily & 5 & $0.96(0.74-1.26)$ & $35(0-76)$ & $0.90(0.72-1.13)$ & $2(0-80)$ & $0.93(0.71-1.21)$ & $10(0-81)$ \\
\hline \multicolumn{8}{|l|}{ Duration of use } \\
\hline$<5$ years & 5 & $0.93(0.74-1.17)$ & $0(0-34)$ & $0.85(0.67-1.09)$ & $0(0-40)$ & $0.81(0.62-1.06)$ & $0(0-67)$ \\
\hline$\geq 5$ years & 5 & $1.09(0.76-1.57)$ & $64(6-86)$ & $1.05(0.71-1.55)$ & $65(7-87)$ & $1.04(0.70-1.54)$ & $59(0-85)$ \\
\hline \multicolumn{8}{|l|}{ Non-aspirin NSAID use } \\
\hline Nonuser (< weekly use) & & 1.00 & & 1.00 & & 1.00 & \\
\hline At least weekly & 6 & $1.34(1.01-1.78)$ & $58(0-83)$ & $1.20(0.89-1.62)$ & $57(0-83)$ & $1.16(0.86-1.56)$ & $49(0-80)$ \\
\hline Weekly-<daily & 5 & $1.18(0.63-2.23)$ & $68(18-88)$ & $0.99(0.50-1.98)$ & $70(22-88)$ & $0.97(0.50-1.89)$ & $64(4-86)$ \\
\hline At least daily & 5 & $1.51(1.04-2.21)$ & $39(0-78)$ & $1.42(0.95-2.12)$ & $41(0-78)$ & $1.42(0.92-2.18)$ & $37(0-76)$ \\
\hline \multicolumn{8}{|l|}{ Duration of use } \\
\hline$<5$ years & 5 & $1.13(0.81-1.57)$ & $34(0-75)$ & $1.04(0.79-1.36)$ & $0(0-79)$ & $1.02(0.77-1.37)$ & $0(0-78)$ \\
\hline$\geq 5$ years & 5 & $1.76(1.27-2.43)$ & $9(0-81)$ & $1.63(1.10-2.43)$ & $28(0-72)$ & $1.57(1.09-2.26)$ & $7(0-81)$ \\
\hline \multicolumn{8}{|l|}{ Any NSAID use } \\
\hline Nonuser (< weekly use) & & 1.00 & & 1.00 & & 1.00 & \\
\hline At least weekly & 6 & $1.14(0.85-1.53)$ & $74(41-87)$ & $1.04(0.81-1.34)$ & $61(4-84)$ & $1.00(0.76-1.32)$ & $61(4-84)$ \\
\hline Weekly-<daily & 5 & $1.05(0.64-1.72)$ & $64(5-86)$ & $0.92(0.55-1.56)$ & $65(8-87)$ & $0.84(0.49-1.42)$ & $59(0-85)$ \\
\hline At least daily & 5 & $1.14(0.78-1.66)$ & $70(23-88)$ & $1.04(0.74-1.46)$ & $58(0-84)$ & $1.01(0.69-1.47)$ & $57(0-84)$ \\
\hline \multicolumn{8}{|l|}{ Duration of use } \\
\hline$<5$ years & 5 & $0.92(0.74-1.14)$ & $0(0-71)$ & $0.84(0.67-1.06)$ & $0(0-46)$ & $0.80(0.62-1.03)$ & $0(0-70)$ \\
\hline$\geq 5$ years & 5 & $1.17(0.74-1.84)$ & $80(52-91)$ & $1.10(0.69-1.73)$ & 77 (44-91) & $1.05(0.67-1.64)$ & 71 (26-89) \\
\hline
\end{tabular}

aModels included terms for age (<50, 50-59, 60-69, $\geq 70$ years), sex (except NDB, all male), education (school only, tech/diploma, university), smoking status (never, former, current) and body mass index $\left(<25,25-29.9, \geq 30 \mathrm{~kg} / \mathrm{m}^{2}\right)$.

${ }^{b}$ Models adjusted for same factors as (a) but also GERD symptoms (less than weekly, at least weekly). 
Table 2 Odds Ratios and 95\% Confidence Intervals for the Association Between Frequency of Non-steroidal Antiinflammatory Drug Use and Risk of Barrett's Esophagus Compared with GERD Controls

\begin{tabular}{|c|c|c|c|c|c|}
\hline & $\begin{array}{l}\text { No. of } \\
\text { studies }\end{array}$ & OR $(95 \% \mathrm{Cl})$ & $\begin{array}{c}P^{2} \\
(95 \% \text { UI) }\end{array}$ & $\mathrm{OR}^{\mathrm{a}}(95 \% \mathrm{Cl})$ & $\begin{array}{c}R^{2} \\
(95 \% \text { UI) }\end{array}$ \\
\hline \multicolumn{6}{|l|}{ Aspirin use } \\
\hline Nonuser (< weekly use) & & 1.00 & & 1.00 & \\
\hline At least weekly & 5 & $1.18(0.92-1.52)$ & $57(0-84)$ & $1.04(0.82-1.30)$ & $40(0-78)$ \\
\hline Weekly-<daily & 4 & $1.17(0.83-1.64)$ & $13(0-87)$ & $1.06(0.78-1.46)$ & $2(0-85)$ \\
\hline At least daily & 4 & $0.97(0.61-1.54)$ & $72(21-90)$ & $0.83(0.51-1.33)$ & $69(11-89)$ \\
\hline \multicolumn{6}{|l|}{ Duration of use } \\
\hline$<5$ years & 4 & $0.98(0.61-1.58)$ & $74(26-91)$ & $0.89(0.53-1.48)$ & $75(30-91)$ \\
\hline$\geq 5$ years & 4 & $1.27(1.02-1.59)$ & $0(0-78)$ & $1.14(0.90-1.45)$ & $0(0-73)$ \\
\hline \multicolumn{6}{|l|}{ Non-aspirin NSAID use } \\
\hline Nonuser (< weekly use) & & 1.00 & & 1.00 & \\
\hline At least weekly & 5 & $0.92(0.69-1.23)$ & $51(0-82)$ & $0.94(0.76-1.16)$ & $3(0-80)$ \\
\hline Weekly-<daily & 4 & $0.85(0.62-1.15)$ & $0(0-82)$ & $0.85(0.62-1.18)$ & $0(0-80)$ \\
\hline At least daily & 4 & $0.89(0.56-1.43)$ & $54(0-85)$ & $0.93(0.62-1.39)$ & $32(0-76)$ \\
\hline \multicolumn{6}{|l|}{ Duration of use } \\
\hline$<5$ years & 4 & $0.83(0.58-1.17)$ & $30(0-74)$ & $0.84(0.62-1.13)$ & $0(0-83)$ \\
\hline$\geq 5$ years & 4 & $0.97(0.71-1.32)$ & $0(0-64)$ & $1.00(0.72-1.38)$ & $0(0-73)$ \\
\hline \multicolumn{6}{|l|}{ Any NSAID use } \\
\hline Nonuser (< weekly use) & & 1.00 & & 1.00 & \\
\hline At least weekly & 5 & $1.07(0.86-1.34)$ & $52(0-82)$ & $0.99(0.82-1.19)$ & $19(0-83)$ \\
\hline Weekly-<daily & 4 & $1.05(0.81-1.36)$ & $0(0-39)$ & $1.00(0.76-1.31)$ & $0(0-17)$ \\
\hline At least daily & 4 & $0.99(0.71-1.38)$ & $59(0-86)$ & $0.90(0.68-1.20)$ & $37(0-78)$ \\
\hline \multicolumn{6}{|l|}{ Duration of use } \\
\hline$<5$ years & 4 & $0.84(0.62-1.14)$ & $44(0-81)$ & $0.79(0.56-1.10)$ & $48(0-83)$ \\
\hline$\geq 5$ years & 4 & $1.12(0.90-1.39)$ & $0(0-74)$ & $1.03(0.82-1.29)$ & $0(0-57)$ \\
\hline
\end{tabular}

a Models included terms for age ( $<50,50-59,60-69, \geq 70$ years), sex (except NDB, all male), education (school only, tech/diploma, university), smoking status (never, former, current) and body mass index (<25, 25-29.9, $\geq 30$ $\left.\mathrm{kg} / \mathrm{m}^{2}\right)$. 
Table 3 Adjusted Odds Ratios and 95\% Confidence Intervals for the Association Between Frequency of Non-steroidal Anti-inflammatory Drug Use and Risk of Barrett's Esophagus Compared with Population-based Controls, Stratified by GERD Symptoms

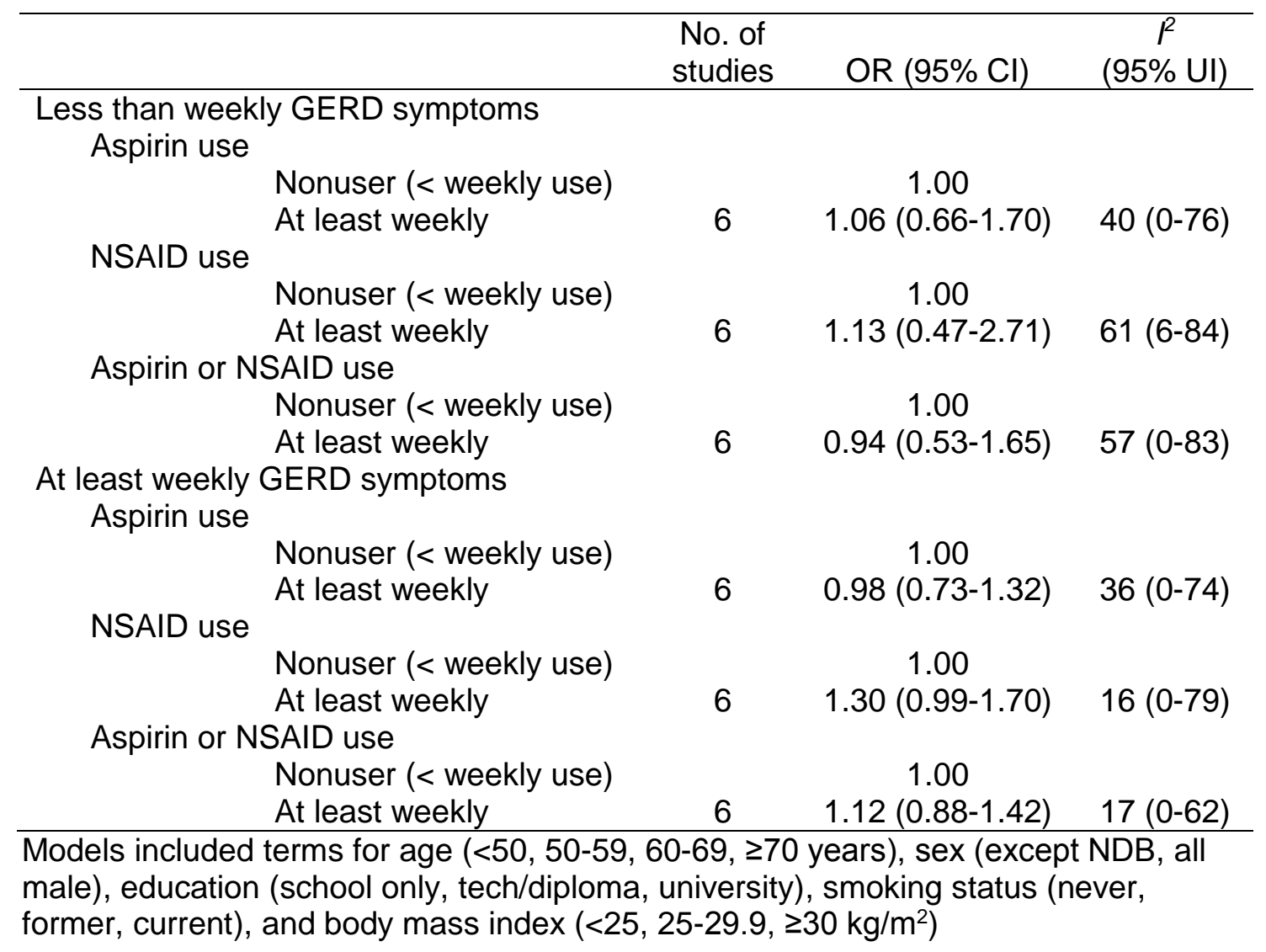

